\title{
No guts, no glory: Visceral ischemia and acute type B aortic dissections
}

\author{
Maral Ouzounian, MD, PhD
}

See related article on pages 1081-6.

Visceral ischemia is a catastrophic complication that afflicts $7 \%$ of patients with acute type B aortic dissection and is associated with a 9-fold increased risk of inhospital mortality. ${ }^{1,2}$ Jonker and colleagues ${ }^{3}$ report an analysis of patients with acute type B aortic dissection and visceral ischemia, along with visceral ischemia, a challenging scenario that is difficult to diagnose early and is often fatal without intervention. The authors observed that the rates of surgery for the management of visceral ischemia have declined over time, from $46.5 \%$ in the early era (1996-2001) to $16.1 \%$ in the most recent era (2008-2012), whereas rates of endovascular intervention increased from $34.9 \%$ to $67.7 \%$ during the same time interval. Furthermore, mortality rates were similar after surgical and endovascular management of visceral ischemia ( $25.8 \%$ and $25.5 \%, P$ not significant), and medical management was the only independent predictor of mortality in multivariate analysis (odds ratio 5.91, 95\% confidence interval 1.2-31.0, $P=.036$ ).

The generalizability of this study is its greatest strength. Rather than focusing on a single-center experience with a predilection for certain therapies, the authors report data from the International Registry of Aortic Dissection, a multicenter registry that has been enrolling patients with acute aortic dissection since 1996. By including patients regardless of their clinical status or treatment strategy, the data in this registry offer insight into the "real-world" experience of patients with acute type B aortic dissection. This analysis includes the largest unselected consecutive patient cohort who have this condition and visceral ischemia, and is therefore of great value to the reader.

Visceral ischemia can be difficult to diagnose, as many of the signs appear late in the process and may be obscured in a patient who is sedated and intubated. The diagnosis is often made by a combination of clinical signs (a distended and

\footnotetext{
From the Division of Cardiac Surgery, Department of Surgery, Peter Munk Cardiac Centre, University of Toronto, Toronto, Ontario, Canada.

Disclosures: Author has nothing to disclose with regard to commercial support.

Received for publication Jan 13, 2015; accepted for publication Jan 14, 2015; available ahead of print Feb 19, 2015.

Address for reprints: Maral Ouzounian, MD, PhD, Peter Munk Cardiac Centre, 200 Elizabeth St, 4N-464, Toronto, ON M5G 2C4, Canada (E-mail: Maral. ouzounian@uhn.ca).

J Thorac Cardiovasc Surg 2015;149:1087-8

$0022-5223 / \$ 36.00$

Copyright (c) 2015 by The American Association for Thoracic Surgery http://dx.doi.org/10.1016/j.jtcvs.2015.01.022
}

tender abdomen, biochemical evidence of liver and pancreatic insufficiency, lactic acidosis) and radiographic findings (severe compression of the true lumen across the visceral segment, compromised flow to the celiac axis and/ or superior mesenteric artery, ischemia of visceral organs). Diagnostic laparoscopy or laparotomy may confirm decreased viability or necrosis of the gut, although this is often a late finding.

The observation in this report that preoperative limb ischemia $(28 \%$ vs $7 \%, P<.001)$ and acute renal failure $(41 \%$ vs $14 \%, P<.001)$ were more common among patients with visceral ischemia is an important one. ${ }^{3}$ Clinicians should have a high index of suspicion that patients with limb or renal malperfusion may have visceral malperfusion in addition. The identification of a sensitive and specific early diagnostic marker of visceral ischemia would be very useful clinically, as early intervention is paramount for a successful outcome.

The prognostic importance of visceral malperfusion is primarily determined by the severity and duration of ischemia. A patient with mild transient organ ischemia will fare better than one with a profound lactic acidosis secondary to infarcted bowel. The lack of details regarding the severity and duration of visceral ischemia in this cohort is a limitation of this study. Furthermore, the mechanism of malperfusion may have important implications for treatment and was unavailable for reporting in this article. Two mechanisms have been identified as the primary causes of organ ischemia after aortic dissection: (1) dynamic obstruction secondary to a collapsed true lumen (Figure 1); and (2) static obstruction with branch vessel obstruction secondary to extension of the dissection/ thrombus into visceral arteries or branch avulsion., ${ }^{4,5}$

Treatment of visceral malperfusion has evolved from open aortic fenestration, first performed in $1935^{6}$ and now used only infrequently, to an endovascular-first approach. Dynamic obstruction may be relieved percutaneously by: (1) proximal stent placement to increase flow in the true lumen; or (2) fenestration to equalize pressures across the septum. Static obstruction likely needs more focal treatment of the malperfused branch by peripheral stenting. Intravascular ultrasound may be particularly helpful in determining the relative sizes of the lumina, location and size of spontaneous fenestrations, characteristics of the mobile flap, as well as the diameter of the major branch arteries and their relationship to any communications. A better understanding of the physiology and imaging of static and dynamic branch vessel obstruction will be important in directing the treatment 


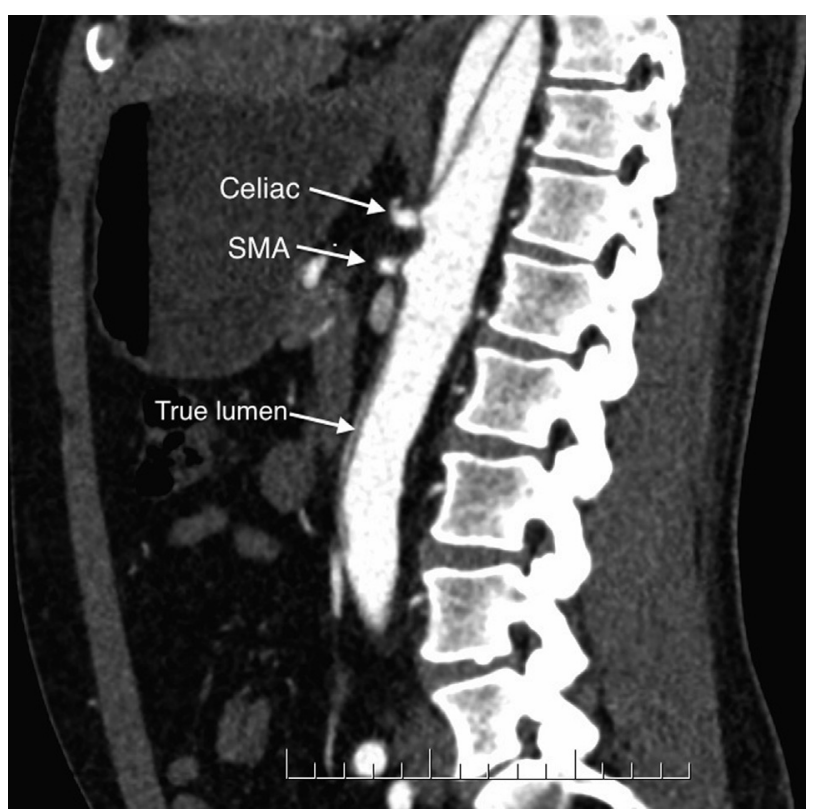

FIGURE 1. Acute type B dissection with visceral ischemia. Dynamic obstruction of mesenteric arteries by a compressed true lumen with the flap prolapsing into the celiac and superior mesenteric arteries. The patient had an acute type B dissection complicated by severe visceral ischemia. $S M A$, Superior mesenteric artery.

of patients with ischemic complications of acute aortic dissection.
Jonker and colleagues ${ }^{3}$ answer several questions and prompt us to ask others: What was the severity and temporal course of the visceral malperfusion in this cohort? What was the mechanism of branch vessel compromise? Was bowel resection necessary? Which patients experienced radiologic and/or clinical resolution of the malperfusion? What surgical techniques and adjuncts led to successful patient outcomes? This important paper sets the framework for future investigations regarding the etiology and treatment of patients with acute type B aortic dissection and visceral malperfusion.

\section{References}

1. Tolenaar JL, Froehlich W, Jonker FH, Upchurch GR Jr, Rampoldi V, Tsai TT, et al. Predicting in-hospital mortality in acute type B aortic dissection: evidence from International Registry of Acute Aortic Dissection. Circulation. 2014;130(11 Suppl 1):S45-50.

2. Fattori R, Cao P, De Rango P, Czerny M, Evangelista A, Nienaber C, et al. Interdisciplinary expert consensus document on management of type B aortic dissection. J Am Coll Cardiol. 2013;61:1661-78.

3. Jonker FH, Patel HJ, Upchurch GR, Williams DM, Montgomery DG, Gleason TG, et al. Acute type B aortic dissection complicated by visceral ischemia. J Thorac Cardiovasc Surg. 2015;149:1081-6.

4. Dake MD, Kato N, Mitchell RS, Semba CP, Shimono T, Hirano T, et al. Endovascular stent graft placement for the treatment of acute aortic dissection. N Engl J Med. 1999;340:1546-52.

5. Williams DM, Lee DY, Hamilton BH, Marx MV, Narasimham DL, Kazanjian SN, et al. The dissected aorta: percutaneous treatment of ischemic complicationsprinciples and results. J Vasc Interv Radiol. 1997;8:605-25.

6. Gurin D, Bulmer JW, Derby R. Dissecting aneurysm of the aorta: diagnosis and operative relief of acute arterial obstruction due to this cause. NY State J Med. $1935 ; 35: 1200-2$. 